\title{
ENSINO MÉDIO POLITÉCNICO NO RS: UM OLHAR A PARTIR EXPERIÊNCIA DE SUPERVISORES DE ESTÁGIO DE UM CURSO DE LICENCIATURA EM MATEMÁTICA NA MODALIDADE A DISTÂNCIA
}

\author{
Rita de Cassia de Souza Soares Ramos ${ }^{1}$ \\ Thaís Philipsen Grützmann ${ }^{2}$
}

O presente estudo é o resultado de uma pesquisa realizada em $2013 \mathrm{com}$ 54 professores de estágio de um curso de licenciatura em matemática na modalidade a distância, em uma universidade pública do Rio Grande do Sul. A pesquisa teve como objetivo compreender o processo de constituição e consolidação do Ensino Médio Politécnico na disciplina de Matemática de escolas estaduais em municípios atendidos pelo curso estudado.

Inicialmente se apresenta o curso, situando as disciplinas de Estágio Curricular Supervisionado, suas características e propostas, bem como a equipe docente que nela trabalha, e de que forma a mesma se organiza.

Após, são consideradas as formas de comunicação entre os membros da equipe, e de que maneira os mesmos se puseram em movimento para discutir o Ensino Médio Politécnico nos 85 Municípios de atuação dos estagiários do CLMD.

Mediante a Análise Textual Discursiva, identificam-se os temas e estratégias julgados de maior valor pelo grupo, e quais suas percepções frente às realidades vivenciadas durante as supervisões dos Estágios Curriculares Supervisionados do curso.

\section{O CURSO DE LICENCIATURA EM MATEMÁTICA A DISTÂNCIA NA UFPEL E O ESTÁGIO CURRICULAR SUPERVISIONADO}

O CLMD - Curso de Licenciatura em Matemática a Distância - é o primeiro curso de graduação na modalidade a distância da Universidade Federal de Pelotas. Teve início em 2006 através do Projeto Pró-Licenciatura, e em 2008 aderiu ao Programa Universidade Aberta do Brasil, ambos oferecidos pelo Governo Federal. No total, já ofereceu 49 turmas em 34 polos, sendo um em Santa Catarina, 
um no Paraná e os demais no Rio Grande do Sul (SOARES e GRÜTZMANN, 2011; GRÜTZMANN, 2013; SALAZAR et al, 2013).

O curso trabalha tanto com práticas pedagógicas como aulas expositivas, gravadas em vídeo ou transmitidas ao vivo, via web conferência, com o apoio de uma lousa digital e de apostilas produzidas pelos professores do curso, bem como da ferramenta fórum, com a característica de fórum de dúvidas. As práticas pedagógicas também consideram as relações entre os sujeitos envolvidos (estudantes, tutores e professores), através da realização de reuniões, de fóruns de discussão e grupos de estudo, com o Ambiente Virtual de Aprendizagem Moodle, sistematicamente atualizado e amplamente explorado com a utilização de mais ferramentas para diversificar as estratégias de ensino-aprendizagem (SALAZAR et al, 2013).

No caso dos Estágios Curriculares Supervisionados, a primeira versão do curso (2006 a 2010) apresentava um modelo em quatro estágios, sendo dois de pesquisa do entorno e dois de regência de classe, conforme descrito por Soares e Grützmann (2011):

Estágio para a Matemática 1, os acadêmicos vão até as escolas e fazem uma pesquisa histórica e relacionada ao contexto socioeconômico dos alunos, verificam o Projeto Pedagógico e, escolhem uma turma para a regência de classe. Depois, analisam o Plano de Ensino de Matemática referente ao ano escolhido, entrevistam o professor da turma e também alguns alunos. Por fim, elaboram um Plano de Ensino para desenvolver em Estágio para a Matemática 2. Neste segundo semestre eles de fato assumem a regência de classe na turma selecionada, com a carga horária mínima de $25 \mathrm{~h} / \mathrm{a}$, concluindo as atividades mediante a apresentação do Relatório Final de Estágio. Salienta-se que os alunos recebem pelo menos uma visita supervisionada, realizada pelos tutores presenciais. As disciplinas de Estágio para a Matemática 3 e 4 possuem a mesma estrutura de Estágio para a Matemática 1 e 2, respectivamente, porém com turmas do Ensino Médio (p. 7).

A supervisão de estágios era realizada pela equipe composta pelo professor da disciplina e pelos tutores presenciais, e mediada pelos tutores a distância na sede. Com as novas regras de fomento estabelecidas pela CAPES, e pela mudança curricular do curso, a partir de 2011, ocorreram algumas adaptações na proposta de estágio no curso, fazendo uso da perspectiva utilizada e trazendo ideias de educação formal e não formal para o ensino e a aprendizagem, bem como de regência em todos os estágios, conforme Manual de Estágios do Curso: 
semestre (diferente da do quinto semestre). Analogamente, a escolha para o sétimo semestre deverá ser entre estagiar na educação formal ou não formal, e a do oitavo semestre será diversa à escolha do semestre anterior (CLMD, 2012, p. 8).

Os dois primeiros estágios eram realizados com atividades que trabalhavam conceitos de Matemática dos anos finais do Ensino Fundamental e os dois últimos do Ensino Médio. Uma das práticas modificadas foi a escrita do Relatório Final de Estágios, na forma de um Portfólio Semanal e do Relato de Experiência na forma de artigo final da disciplina.

A mediação se deu por uma equipe composta pelo Coordenador de Estágios (professor da UFPel), Professores da Disciplina (Professores da UFPel), Professores Pesquisadores (bolsistas da UAB), denominados no curso de Orientadores, Tutores Presenciais (bolsistas da UAB), denominados de Coorientadores, Tutor a Distância da Disciplina, Supervisores (professores de matemática responsáveis pelas turmas onde os estágios ocorreram) e Instituição (diretores ou responsáveis pelas unidades concedentes de estágio). Todos os sujeitos tiveram participação no acompanhamento e avaliação dos alunos, e a comunicação entre a equipe se deu de diferentes formas, conforme mídias disponíveis.

Em 2013 a referida equipe docente (Coordenação de Estágios, Professores da Disciplina, Orientadores e Coorientadores de Estágio e tutor a distância da disciplina) contava com 54 pessoas. Foi nesta época que os acadêmicos ingressantes de 2010 iniciaram os trabalhos de Estágio no Ensino Médio. Diante dos desafios enfrentados por uma nova modalidade de Ensino Médio no Estado, a Coordenação de Estágios juntamente com a equipe docente propôs um estudo para compreender como se caracterizava o Ensino Médio Politécnico no Rio Grande do Sul.

Em 2012, o CLMD aderiu através da Coordenadoria das Licenciaturas ao Projeto LIFE - Programa de Apoio a Laboratórios Interdisciplinares de Formação de Educadores, proposto pela CAPES, com o subprojeto LAM - Laboratório Multilinguagens, cujos projetos de Ensino, Pesquisa e Extensão contavam com a participação da equipe de estágios. O projeto "Grupo de Estudos de Formação Docente a Distância em Matemática - GEFDDiM", no qual as reuniões semanais de estudo da equipe docente de estágios eram registradas, promoveu o projeto de pesquisa "Ensino Médio Politécnico no RS: um olhar a partir experiência de 
supervisores de estágio de um curso de licenciatura em matemática na modalidade a distância", que intitula este texto.

Assim, em face às mudanças curriculares ocorridas no Estado do Rio Grande do Sul desde 2012, com a inserção do Ensino Médio Politécnico, o grupo de professores de estágio de um curso de licenciatura em matemática na modalidade a distância percebeu a necessidade de compreender as alterações e debater sobre possibilidades de inserção de novas práticas em sua atuação. Este estudo e suas conclusões são descritos a seguir.

\section{COMUNICAÇÃO ENTRE A EQUIPE DE ESTÁGIOS}

As reuniões semanais ocorreram de março a dezembro de 2013. Os participantes da equipe docente se reuniram através de web conferências na rede federal RNP - Rede Nacional de Ensino e Pesquisa. Tais reuniões eram gravadas e o link disponibilizado aos participantes por meio de um grupo em uma rede social, bem como de uma sala de Capacitação de Professores de Estágio no Moodle Ambiente Virtual de Aprendizagem utilizado pelo curso.

A dinâmica das reuniões consistia na participação presencial dos professores de Pelotas e região e online dos participantes de outras regiões, sendo que os estágios regulares contavam com 22 polos de apoio presencial. Inicialmente eram apresentados pelos grupos textos estudados, logo após havia a discussão dos mesmos, e finalizava-se a reunião com questões pontuais de estágio. A comunicação online semanal, além das reuniões, ocorria por meio do grupo na rede social, por e-mail, telefone e no Ambiente Virtual de Aprendizagem.

O público-alvo foi de 54 professores de estágio do curso, participantes do GEFFDiM, sendo que a maior parte dos professores atuava também na rede pública estadual, e orientou e acompanhou os estudantes nos estágios de Matemática do Ensino Médio.

Além das webreuniões, ocorreu uma capacitação presencial na sede, em Pelotas, onde participaram 80 pessoas da equipe, de 22 polos. Entre os principais tópicos abordados nesse momento presencial destacam-se a formação de professores, as modalidades de Estágio Supervisionado, a atuação docente em parceria, identidades docente e discente na Educação a Distância e a atuação dos 
estudantes do CLMD nas escolas de Ensino Médio Politécnico, contando ainda com a participação da Coordenação do Curso e da Coordenação de Tutoria.

\section{METODOLOGIA}

A escolha do grupo pelo tema do Ensino Médio Politécnico levou à seleção dos textos a serem estudados. A coletânea de publicações utilizada foi a dos artigos propostos pela secretaria de educação do estado ARAGONEZ (2013), AZEVEDO; REIS (2013), CHASSOT (2013), FERREIRA (2013), GARCIA (2013), JÉLVEZ (2013), KUENZER (2013), LIMA (2013), MOSNA (2013), NASCIMENTO (2013), ROCHA (2013), SILVA (2013), SOUSA JUNIOR (2013), pois boa parte dos coorientadores participava de capacitações propostas pelas Coordenadorias Regionais de Educação sobre a proposta do Ensino Médio.

Os instrumentos tiveram como foco analisar as diferentes perspectivas trazidas por professores supervisores de estágio cujos alunos realizaram a prática de ensino em mais de 200 escolas, em 85 Municípios do Estado.

Os questionamentos versavam a respeito dos temas e das abordagens dadas pelos grupos nas discussões, bem como ao enfoque dado às escolhas de assuntos e encaminhamentos propostos nas reuniões.

As etapas escolhidas para a pesquisa foram a formação dos grupos e discussão a respeito de textos a serem estudados, a discussão de textos em grupos e apresentação semanal no grande grupo por reunião online, análise de relatos e acompanhamento de estágios no Ensino Médio Politécnico das escolas estudadas e a análise reflexiva dos dados obtidos.

Os dados foram retirados das webreuniões, gravadas em plataforma específica, dos materiais apresentados pelas duplas e trios e dos fóruns de uma rede social na qual professores discutiam situações de estágio. A metodologia utilizada para a compreensão dos dados foi a Análise Textual Discursiva (ATD).

A ATD é "um processo auto-organizado de construção de compreensão em que novos entendimentos emergem a partir de uma sequência recursiva de três componentes" (MORAES e GALIAZZI, 2007, p.12), sendo esses: (a) desconstrução, (b) unitarização e (c) categorização. 
Na ATD, um texto pode ser considerado objetivo em seus significantes, mas não em seus significados, assim, a ATD "opera com significados construídos a partir de um conjunto de textos" (MORAES e GALIAZZI, 2007, p.13), e objetiva descrever e interpretar alguns sentidos que a leitura dos mesmos pode suscitar, sendo que os autores assumem que toda a leitura é uma interpretação.

A ATD assume o texto como significante em relação ao qual é possível exprimir sentidos simbólicos, buscando a construção de compreensões. Nesta metodologia, as leituras podem ser manifestas ou latentes, e perante as mesmas, 0 autor deve pôr em suspenso suas próprias ideias.

A metodologia define que a análise não pode ser feita sem teoria, mesmo que as tácitas do autor. Isso fica claro quando os autores dizem que toda leitura é uma interpretação, e que a análise é uma interpretação. Mesmo as teorias emergentes possuem como pano de fundo as teorias do autor.

Os procedimentos da ATD exigem uma codificação, fazendo que as Unidades de Análise se tornem elementos unitários de um conjunto caótico. A ATD se dá, portanto, em um movimento que vai da ordem ao caos e deste a uma nova ordem, gerando possibilidades inovadoras de compreensão dos fenômenos investigados.

Essa compreensão foi o que este estudo buscou na análise das reuniões, que ocorreram uma ou duas vezes por semana, conforme disponibilidade dos participantes, na tentativa de esclarecer os textos propostos pelo governo aos professores do Ensino Médio e trazendo os enfrentamentos vivenciados na supervisão dos estágios do Curso de Licenciatura em Matemática a Distância.

\section{RESULTADOS E DISCUSSÃO}

Segundo a proposta do Ensino Médio Politécnico no Rio Grande do Sul, as disciplinas deveriam se articular por meio de atividades integradoras entre os eixos principais. São mudanças que perpassam questões de currículo, epistemologia e prática docente, e que se colocam em sala de aula a partir de um programa de governo, pressionando os professores a se encaixarem, para produzir conhecimentos que tenham a ver com as mudanças sociais promovidas pela era da informação. 
A equipe que propôs o formato de estágios em conjunto com a equipe de supervisão de estágios levou em conta estas questões para organizar a discussão e pensar em como promover o estágio docente para um currículo em transformação.

Mediante as discussões realizadas no grupo foi realizado um mapeamento dos estágios no Estado, e dos 85 Municípios atendidos, todos estavam atuando com o Ensino Médio Politécnico. A abrangência e heterogeneidade, bem como o número de escolas pesquisadas, em regiões não próximas, gerou no grupo uma visão ampla das diversas realidades encontradas no Estado.

Após a categorização dos dados, o estudo apontou algumas unidades de análise, que têm relação com os assuntos abordados no material proposto pelo governo do Estado à época da pesquisa. Os temas estudados foram Democratização, Legislação, Juventudes, Formação de Professores, Educação Profissional, Pesquisa como princípio pedagógico, Interdisciplinaridade, Trabalho e Avaliação (AZEVEDO e REIS, 2013).

Cada um dos temas foi apresentado de forma online síncrona por um pequeno grupo, e nas discussões vale destacar a experiência dos professores que estavam supervisionando os estágios, em conjunto com a experiência dos professores que propuseram o formato de estágios para a turma de licenciandos.

Questões de ordem prática, como de que forma estabelecer o currículo nas escolas com as diretrizes encontradas no material, e de ordem de análise, como qual o papel da Universidade e da Escola na democratização e mudança curricular no Ensino Médio, levando em conta aspectos do estágio Curricular Supervisionado, permearam as discussões do grupo.

As categorias que seguem foram encontradas na análise dos textos estudados:

Formação - A formação em serviço dos professores foi organizada pelas CREs (Coordenadorias Regionais de Educação), em parceria com as Universidades, utilizando os materiais propostos pelo governo. A participação dos professores foi, segundo o grupo, parcial. Reparou-se que de acordo com a região do Estado, a presença e participação nas formações era maior, no entanto, os dados foram insuficientes para elucidarmos as causas que levaram algumas regiões a apostarem na proposta e outras a desacreditarem.

Equipamentos - A maior parte dos Municípios recebeu equipamentos de laboratório e tecnologias, como lousas digitais e computadores portáteis. Muitos dos 
equipamentos recebidos não foram utilizados pelos professores das escolas, e os participantes que trabalham em escolas afirmaram não haver a devida manutenção. No entanto, afirmaram que os estagiários fizeram uso dos mesmos, e um dos fatores alegados foi a proximidade com a tecnologia que o aluno da modalidade a distância vivencia.

Proposta metodológica - A mudança curricular foi realizada de forma arbitrária, sem a consulta aos professores, apesar disso, muitos buscavam o engajamento. O CLMD, pela sua estrutura curricular e pelos estágios na educação não formal, na visão dos professores, dava maiores condições às discussões a respeito de atividades integradoras, no entanto, o trabalho interdisciplinar proposto nos textos era visto de formas bastante diferenciadas nas regiões do Rio Grande do Sul. Uma das hipóteses levantadas foi a liberdade de interpretação à proposta sugerida pelo material, e pelos encaminhamentos nas formações regionais.

Democratização - O papel da Escola e da Universidade frente à proposta de democratização do ensino. Quais os elementos dos estágios supervisionados que podem contribuir com a democratização, e de que forma. Os professores sugeriram que para haver democratização há a necessidade de ensino e aprendizagem de certos conceitos, refletindo sobre os conteúdos de Matemática do Ensino Médio. As discussões chegaram à conclusão que existe uma mudança que não dá conta do que conhecemos por escola.

Percebeu-se que as maiores mudanças estão na perspectiva interdisciplinar abordada pelos seminários integradores, na articulação entre as áreas do saber, nas possibilidades de compreensão das realidades nos projetos de ensino e na mudança drástica da carga horária e grade curricular.

\section{CONCLUSÃO}

A pesquisa avançou em discussões na área de Educação Matemática frente às perspectivas de formação docente na graduação, como formação do licenciado para o trabalho na educação básica, buscando a transformação das realidades a partir da compreensão das mesmas. Indicou que o curso deveria promover a pesquisa em ação com os estagiários e corroborou com o formato de estágios adotado pelo curso. Apontou também para a diversidade de olhares sobre a mesma proposta, nas diferentes regiões do Estado. 
Além das discussões a respeito dos textos, vale dizer que uma grande contribuição deste estudo vem no sentido de aproximar o professor universitário do professor que atua em escolas de educação básica, para, a partir de uma discussão fundamentada nas vivências de sala de aula e nas mudanças que ocorrem nas escolas se constitua uma proposta de estágios em Licenciatura em Matemática.

\section{REFERÊNCIAS}

ARAGONEZ, I. B. Trabalho como princípio educativo na prática pedagógica real. In: AZEVEDO, J. C.; REIS, J. T. Reestruturação do Ensino Médio: Pressupostos teóricos e desafios da prática. São Paulo: Fundação Santillana, 2013, p.165-186.

AZEVEDO, J. C.; REIS, J. T. Democratização do Ensino Médio: a reestruturação curricular no RS. In: AZEVEDO, J. C.; REIS, J. T. Reestruturação do Ensino Médio: Pressupostos teóricos e desafios da prática. São Paulo: Fundação Santillana, 2013, p. 25-48.

CHASSOT, A. Prefácio - Um prelúdio para outro Ensino Médio. In: AZEVEDO, J. C.; REIS, J. T. Reestruturação do Ensino Médio: Pressupostos teóricos e desafios da prática. São Paulo: Fundação Santillana, 2013, p. 7-14.

CLMD. Curso de Licenciatura em Matemática a Distância da Universidade Federal de Pelotas. Manual de Estágios. 2012, 42p.

FERREIRA, V. M. Ensino Médio Politécnico: mudança de paradigmas. In: AZEVEDO, J. C.; REIS, J. T. Reestruturação do Ensino Médio: Pressupostos teóricos e desafios da prática. São Paulo: Fundação Santillana, 2013, p.187-206.

GARCIA, S. R. O. Ensino Médio e Educação Profissional: breve histórico a partir da LDBEN no 9394/96. In: AZEVEDO, J. C.; REIS, J. T. Reestruturação do Ensino Médio: Pressupostos teóricos e desafios da prática. São Paulo: Fundação Santillana, 2013, p. 49-64.

GRÜTZMANN, T. P. Os Saberes Docentes na Tutoria em Educação a Distância. Tese (Doutorado em Educação) - Programa de Pós-Graduação em Educação. Faculdade de Educação. Universidade Federal de Pelotas, Pelotas, 2013. 259f.

JÉLVEZ, J. A. Q. A pesquisa como princípio pedagógico no Ensino Médio. In: AZEVEDO, J. C.; REIS, J. T. Reestruturação do Ensino Médio: Pressupostos teóricos e desafios da prática. São Paulo: Fundação Santillana, 2013, p. 117-138.

KUENZER, A. Z. Dilemas da formação de professores para o Ensino Médio no século XXI. In: AZEVEDO, J. C.; REIS, J. T. Reestruturação do Ensino Médio: Pressupostos teóricos e desafios da prática. São Paulo: Fundação Santillana, 2013, p. 81-96. 
LIMA, M. G. M. Aprendizagem versus reprovação no contexto do Ensino Médio brasileiro. In: AZEVEDO, J. C.; REIS, J. T. Reestruturação do Ensino Médio: Pressupostos teóricos e desafios da prática. São Paulo: Fundação Santillana, 2013, p. 207-218.

MORAES, R.; GALIAZZI, M. C. Análise Textual Discursiva. ljuí: Ed. Unijuí, 2007.

MOSNA, R. M. P. Avaliação: paradigmas e paradoxos no âmbito do Ensino Médio. In: AZEVEDO, J. C.; REIS, J. T. Reestruturação do Ensino Médio: Pressupostos teóricos e desafios da prática. São Paulo: Fundação Santillana, 2013, p. 219 240.

NASCIMENTO, M. E. P. Apresentação. In: AZEVEDO, J. C.; REIS, J. T. Reestruturação do Ensino Médio: Pressupostos teóricos e desafios da prática. São Paulo: Fundação Santillana, 2013, p. 15-24.

ROCHA, S. J. S. Interdisciplinaridade: possibilidades na prática curricular. In: AZEVEDO, J. C.; REIS, J. T. Reestruturação do Ensino Médio: Pressupostos teóricos e desafios da prática. São Paulo: Fundação Santillana, 2013, p.139-164.

SALAZAR, S. B.; HOFFMANN, D. S.; FANTINEL, P. C.; ANGELO, N. P.; RAMOS, R. C. S. S. A História Em Construção do CLMD/CEAD/UFPel a partir do núcleo docente efetivo. In: X ESUD 2013 - X Congresso Brasileiro de Ensino Superior a Distância. Belém/PA, 11 - 13 de junho de 2013, p. 1-12.

SILVA, M. R. Juventudes e Ensino Médio: possibilidades diante das novas DCN. In: AZEVEDO, J. C.; REIS, J. T. Reestruturação do Ensino Médio: Pressupostos teóricos e desafios da prática. São Paulo: Fundação Santillana, 2013, p.65-80.

SOARES, S. S.; GRÜTZMANN, T. P. A afetividade na relação tutor-aluno no período do estágio. Dialógica (Manaus), v. 1, p. 1-12, 2011.

SOUSA JUNIOR, J. Educação profissional e educação geral: desafios da integração no Ensino Médio. In: AZEVEDO, J. C.; REIS, J. T. Reestruturação do Ensino Médio: Pressupostos teóricos e desafios da prática. São Paulo: Fundação Santillana, 2013, p. 97-116. 